\title{
Evaluation of VMA and Film Thickness Requirements in Hot-Mix Asphalt
}

\author{
Haydar R. Hmoud \\ College of Engineering, Baghdad University, Baghdad, Iraq
}

Received: May 31, 2011

Accepted: June 17, 2011

doi:10.5539/mas.v5n4p166

\begin{abstract}
The asphaltic mixture consists of three main parts: the aggregate, the binder and air voids between the granules. The percentage of air void is important, where high air voids will produce crack sensitive pavement due to oxidation of asphalt or filling the voids by water which will cause striping of aggregate. The asphalt content is important too, where low content will increase stiffness of pavement and high content will increase skidding problems, therefore; the sum of air voids and asphalt content is called Voids in Mineral Aggregate (VMA), where it had been found by several researchers and transportation departments that VMA depends on maximum aggregate size where, for $19 \mathrm{~mm}$ maximum aggregate size, VMA is $14 \%$ and $13 \%$ for $12.5 \mathrm{~mm}$ aggregate size. Besides VMA, it had been found that average thickness of asphalt film coating the aggregate of 8 microns will produce durable mixture. VMA limit has not been included in Iraqi standards, therefore, this study focused on collecting literatures on these parameters, analyzing mixtures prepared under current standards to evaluate VMA and film thickness where, for surface course $(12.5 \mathrm{~mm}$ aggregate size) VMA was $10 \%$ and film thickness was 9 microns and for binder course (19 mm aggregate size) VMA was 10\% and film thickness was 9.6 microns. The final conclusion was to use VMA and film thickness as parameters in the design of asphaltic mixture as well as current standards and the study included the necessary equations to be used in the calculations of VMA and average film thickness.
\end{abstract}

Keywords: VMA, Film thickness, Hot mix asphalt, Asphalt concrete, Aggregate

\section{Introduction}

The importance of volumetric analysis of hot asphaltic concrete mixtures has been studied by several researchers since 1950's, and voids in mineral aggregates was one of the most important parameters in volumetric analysis, therefore most agencies has been determined limits for the minimum rates of voids in mineral aggregate along with standard specifications like Marshall, Hveem and Superpave mix design methods. The effect of asphalt film thickness was also studied because it was found that, to obtain durable mixture of asphaltic concrete, then coating of aggregates should be assured for a certain average thickness $(6-8$ microns $)$ and voids in mineral aggregate should be maintained to limits according to nominal maximum aggregate size.

The objective of this study is: to review the work implemented by several researchers and agencies to establish a foundation for these parameters in Iraq to help for further work, to evaluate mixtures of asphaltic concrete prepared by current standards according to the volumetric parameters (VMA and film thickness) and finally to suggest limits of VMA and film thickness to be added to the Iraqi standards. To achieve these targets the work divided into three main parts, the first is review of literatures, where definitions and main results where collected about VMA and film thickness. Also, equations for calculating volumetric analysis of asphaltic concrete where collected. The second part represents the work of evaluation mixtures prepared by current standards to the suggested percent of VMA and average film thickness and the discussion of results. Finally, submitting a conclusion of the study according to the results obtained.

\section{Related Work}

Voids in Mineral Aggregate (VMA) defined by Asphalt Institute Manual Series (MS-4 2007) as the volume of intergranular void space between the aggregate particles of a compacted paving mixture that includes the air voids and the effective asphalt content, expressed as a percentage of the total volume of the compacted paving mixture, Fig. 1 shows main components of typical hot mix asphalt concrete.

In a historical display of the researches done on VMA, a study was presented by Coree, et.al (1998) where they stated that McLeod (1955) presented his initial analysis on "the voids properties of compacted paving mixtures", in which he laid out the basic principles of a minimum VMA requirement where he suggested $15 \%$ as minimum VMA in HMA where mixtures of high voids will produce brittle and crack sensitive pavements and mixtures of less voids will produce pavements subjected to rutting and permanent deformation...etc. Also, he was concerned that specifications with requirements on both air voids and VFA were too restrictive at higher asphalt contents. More importantly, he suggested that the VFA requirement would allow a pavement to be constructed with 3.76 percent asphalt, which he felt was too low for durability. They summarized the principal factors influencing VMA as follows: 
1. For any given particle size, the Fuller or Weymouth curve should produce maximum density.

2. Moving off the maximum density curve (To either side) should provide less density and more VMA.

3. Using slightly more (or less) fine aggregate should open space between the coarser particles resulting in higher VMA.

4. Using appreciably less fine aggregate will result in an "open graded" mixture with relatively high VMA.

5. If the quantity of fine material ranges from slightly less to appreciably more than the Fuller curve, the VMA in the resulting dense graded mixture will increase steadily (slowly) but so will the required asphalt content such that the air voids will still be in the range of 3-5 percent.

6. Choosing to add or reduce fine aggregate depends on (1) required pavement surface texture, (2) whether or not the resulting pavement would be durable enough for local climate and traffic conditions, and (3) relative cost of coarse and fine aggregates.

7. Adding mineral filler can drastically reduce VMA. Hence reducing mineral filler can rapidly increase VMA. The work of asphalt institute was also included in the historical display, where the work agreed with McLeod's work by using minimum VMA requirements with the Marshall mix design method.

In another research Aschenbrenner and MacKean examined 101 mix designs to determine which maximum density line (MDL) worked best for predicting VMA, achieving the best correlation with the Superpave definition. They report that in 1993, the first year the Colorado Department of Transportation specified a minimum VMA, the average mix design asphalt content increased 0.46 percent. Also, they examined 24 laboratory mixes to study the effects of four variables on VMA:

1. Gradation,

2. Percent passing $75 \mu \mathrm{m}$ sieve,

3. Size distribution passing $75 \mu \mathrm{m}$ sieve, and

4. The fine aggregate angularity.

They found that gradation played a role in influencing VMA, but got such poor correlation that VMA could not effectively be predicted from gradation. The percent passing the $75 \mu \mathrm{m}$ sieve has a significant effect on VMA, particularly for gradations on the fine side of the MDL. Lower percent passing $75 \mu \mathrm{m}$ sieve increased VMA, higher reduced VMA. They recommended that the fine aggregate be kept well off the MDL. Their results examining size distribution passing the $75 \mu \mathrm{m}$ sieve were inconclusive. They found aggregate angularity to substantially affect the VMA, with crushed aggregates providing more VMA and rounded aggregates less. The fine aggregate angularity was more influential for coarse mixes or mixes following the MDL than for mixes on the fine side of the MDL. As a result of the historical display, Coree et.al concluded that the minimum average film thickness also needs to verified and related to field performance. The surface area factors and shape constants dating back to the 1940's need to be examined using modern technology.

Kandhal (1985) reported there were still problems with the VMA criterion: The VMA is considered to be the most important mix design parameter which affects the durability of the asphaltic concrete mix. High VMA values allow enough asphalt to be incorporated into the mix to obtain maximum durability without the mix flushing. Additionally, such mixes have the following advantages compared to low VMA mixes:

1. Lower stiffness modulus at low temperatures. This is helpful in minimizing the severity of thermal and reflection cracking.

2. Lower susceptibility to variations in asphalt and fines content during production. Such variations can cause the mix to be too brittle or too rich.

Kandhal et.al (1998) in their review of literature stated that thicker asphalt binder films produced mixes which were flexible and durable, while thin films produced mixes which were brittle, tended to crack and ravel excessively, retarded pavement performance, and reduced its useful service life. On the basis of the data they analyzed, average film thicknesses ranging from 6 to 8 microns were found to have provided the most desirable pavement mixtures. They calculated average film thickness by dividing volume of asphalt by surface area of aggregate. Surface area of aggregate depends on the gradation of aggregate being used in the mixture and surface area factor for each sieve, where surface area calculated by multiplying percent passing of aggregate for a certain sieve by surface area factor of that sieve. Asphalt Institute proposed surface area factors to be used in calculating surface area of aggregate. They also concluded that the film thickness decreases as the surface area of the aggregate is increased. Studies have shown that asphalt mix durability is directly related to asphalt film thickness. Therefore, the minimum VMA should be based on the minimum desirable asphalt film thickness rather than minimum asphalt content because the latter will be different for mixes with different gradations. Mixes with a coarse gradation (and, therefore, low surface area) have difficulty meeting the minimum VMA requirement based on minimum asphalt content in spite of thick asphalt films. A critical review of the minimum VMA requirement is, therefore, needed. Surface area factors for different sieves are shown in Table 1. 
A research submitted by Hislop and Coree (2000) to determine the validity of the minimum VMA requirement vs. nominal maximum aggregate size, and they found that the current requirement shown in Table 2 need to be analyzed statistically to develop an equation and then need to be applied to field and laboratory data, for both well and poorly performing mixes for validation. Zaniewski and Reyes (2003) analyzed volumetric parameters of mixtures prepared by Marshall and Superpave mix design methods using the following equations:

$\mathrm{VTM}=100\left(1-\mathrm{G}_{\mathrm{mb}} / \mathrm{G}_{\mathrm{mm}}\right)$

$\mathrm{VMA}=\left(100-\left[\mathrm{G}_{\mathrm{mb}}\left(1-\mathrm{P}_{\mathrm{b}}\right) / \mathrm{G}_{\mathrm{sb}}\right]^{* 100}\right)$

$\mathrm{VFA}=100(\mathrm{VMA}-\mathrm{VTM} / \mathrm{VMA})$

Where:

$\mathrm{VTM}=$ Voids in total mix (\%).

$\mathrm{VMA}=$ Voids in mineral aggregate $(\%)$.

$\mathrm{VFA}=$ Voids fill with asphalt (\%).

$\mathrm{Gsb}=$ Bulk specific gravity of aggregate.

$\mathrm{Gmb}=$ Bulk specific gravity of compacted mixture.

$\mathrm{Gmm}=$ Maximum theoretical specific gravity of mixture .

$\mathrm{Pb}=$ Percent binder.

They concluded that the volumetric analysis method based on aggregate surface area presents an interesting approach for evaluating average asphalt film thickness. In addition, they concluded that there is a need to properly account for absorbed binder to correctly compute volumetric properties. Also, they concluded that the specific surface area of an aggregate gradation is dominated by the percent of material passing the $0.15 \mathrm{~mm}$ sieve and the surface area factors computed should be computed using the average of the sieve opening for the passing and the retaining sieve and based on the measured values for fine material surface area, if asphalt content remains constant, mixes with limestone fine material will have a much thinner asphalt film thickness than the mixtures made with natural sands.

This factor would indicate limestone mixtures are more rut resistant but more fatigue susceptible than natural sand mixtures. Finally, they concluded that the volumetric analysis method based on the surface area factors ignores the effect of the aggregate shape and texture on the compaction ability of the asphalt concrete mixture. Volumetric parameters are dependent on the compaction effort placed on the mixture. Volumetric analysis based on the surface area is not capable of capturing this factor.

Kandhal and Cooley (2001) concluded in the report of NCHRP 464 that coarse-aggregate type has a significant effect on the VMA of mixes. Coarse, angular granite aggregate generally produced a higher VMA than did the course, crushed gravel aggregate. In the report of SHRP -A-410, Kennedy et.al. (1994) suggested the graph shown in Fig 2 for determining VMA according to air voids and nominal maximum aggregate size. Also, they stated that the Superpave mix design system has three vertically integrated levels of mix design. Level 1 design is a volumetric mix design where aggregate characteristics and mixture volumetric properties, such as air voids and VMA, are the basis for the selection of gradation and asphalt binder content. Level 2 design includes volumetric design and key performance-based mixture tests from which performance is predicted. Level 3, the highest level, includes an expanded series of performance-based tests. A more rigorous prediction of performance is made in level 3. Asphalt film thickness is not directly considered for the design of asphalt concrete. However, research has demonstrated that a desirable coat is needed over the aggregate particles to ensure the performance of the asphalt concrete. A method to calculate the film thickness of an asphalt mix, based on the surface area factors, was developed by Hveem. The following formulas are used to calculate the film thickness (Zaniewski and Reyes 2003):

$\mathrm{T}_{\mathrm{f}}=\left[\mathrm{W}_{\mathrm{b}} /(\mathrm{SA} * 1000)\right] * \mathrm{G}_{\mathrm{b}}$

$\mathrm{W}_{\mathrm{b}}=\mathrm{W}_{\mathrm{b}} / \mathrm{W}_{\mathrm{agg}}$

$\mathrm{w}_{\mathrm{b}}=\mathrm{V}_{\mathrm{b}} * 10 * \mathrm{G}_{\mathrm{b}}$

$\mathrm{V}_{\mathrm{b}}=\mathrm{VMA}-\mathrm{VTM}-\mathrm{P}_{\mathrm{ba}}$

$\mathrm{P}_{\mathrm{ba}}=100\left(\mathrm{G}_{\mathrm{se}}-\mathrm{G}_{\mathrm{sb}} / \mathrm{G}_{\mathrm{se}} * \mathrm{G}_{\mathrm{sb}}\right) * \mathrm{G}_{\mathrm{b}}$

$\mathrm{G}_{\mathrm{se}}=\left(100-\mathrm{P}_{\mathrm{b}}\right) /\left[100 / \mathrm{G}_{\mathrm{mm}}\right]-\left[\mathrm{P}_{\mathrm{b}} / \mathrm{G}_{\mathrm{b}}\right]$

$\mathrm{W}_{\mathrm{agg}}=\left(\mathrm{W}_{\mathrm{b}} / \mathrm{P}_{\mathrm{b}}\right) *\left(100-\mathrm{P}_{\mathrm{b}}\right)$

Where:

$\mathrm{T}_{\mathrm{f}}$ : Average Film Thickness, microns.

$\mathrm{W}_{\mathrm{b}}$ : Weight of binder / kg of aggregate.

$\mathrm{SA}$ : Specific surface area of the aggregate, $\mathrm{m}^{2} / \mathrm{kg}$. 
$\mathrm{G}_{\mathrm{b}}$ : Specific gravity of binder.

$\mathrm{V}_{\mathrm{b}}$ : Volume of binder, $\%$.

$\mathrm{P}_{\mathrm{ba}}$ : Percent of absorbed binder, $\%$.

$\mathrm{G}_{\mathrm{se}}$ : Effective specific gravity of aggregate.

$\mathrm{G}_{\mathrm{sb}}$ : Bulk specific gravity of aggregate.

$\mathrm{P}_{\mathrm{b}}$ : Percent of binder, $\%$.

$\mathrm{G}_{\mathrm{mm}}$ : Maximum theoretical specific gravity of mixture.

$\mathrm{W}_{\text {agg }}$ : Weight of aggregate, $\mathrm{kg}$.

$\mathrm{W}_{\mathrm{b}}$ : Weight of binder, $\mathrm{kg}$.

They stated that previous researchers recognized the relationship between voids, aggregate surface area, binder film thickness and stability for dense graded asphalt concrete mixes. A recommendation of an average asphalt film thickness of 6 to 8 microns was needed for flexible and durable asphalt mixtures. Thinner asphalt films results in mixes that are likely to break, crack, and ravel. An $8 \mu \mathrm{m}$ film thickness was also recommended by NCAT researchers (Kandhal et.al, 1998-1).

Boris Radovskiy (TRB 2003) reviewed the history of VMA and average film thickness where he stated that the minimum voids in the mineral aggregate (VMA) requirement has been a property proposed since the late 1950's for use in asphalt mix design specifications, but difficulties in achieving VMA in mixtures have led to several new research studies. Some researchers recommend using the average asphalt film thickness to supplement the minimum VMA criteria in the volumetric mix design and the conventional calculation of the film thickness does not require any information on porosity of mixture or on degree of compaction. He concluded that a new definition of film thickness is proposed. A fundamentally sound model for film thickness calculation is developed. For that purpose a recent result from statistical geometry of particulated composites was applied. The results of calculations are logical and agree with some important data reported in previous publications.

Nelson (2005) compared between superpave and Marshall mixes of $9.5 \mathrm{~mm}$ maximum aggregate size and found that, the VMA was higher for the Superpave mixes than for the Marshall mixes, but the opposite was true for the mixes with 13 percent sand. Also, he found that the difficulty in achieving minimum VMA requirements in Superpave method can be attributed to the higher compactive effort provided by the Superpave gyratory compactor.

Paul, et.al. (2001) summarized factors affecting VMA where they found that VMA depends on the gradation, surface texture, and particle shape of the aggregate. In designing a mix, all of these characteristics must be considered. When there is difficulty in meeting the minimum VMA requirements, some or all of the above characteristics must be adjusted. It should be remembered that the VMA of a plant-produced mixture is typically lower than the VMA of the laboratory trial mix formula. Allowances should be made for the reduction in VMA that will occur between the laboratory-designed and the plant-produced mixtures.

Diaz (2003) concluded that both the Marshall and Superpave mix design methods use VMA to ensure minimum asphalt content. However, VMA is an indirect measure of effective asphalt content. To remain consistent with current mix design practices VMA criteria were developed using asphalt film thickness. Zanariah (2006) stated that the mixtures volumetric properties including asphalt content, VMA and VFA have been identified as important parameters for performance and VMA is considered the most important parameter and is used in Superpave mixture design specifications to eliminate the use of potentially poor-performing mixtures. He found that even though the gradation of a mix designed close to MDL (Maximum Density Line) but the VMA of that mix was unexpectedly higher than control mix where gradation of control mix was designed away from MDL. This is because the optimum asphalt content determined for the mix was higher than control mix and therefore, this affected the VMA. Also, he summarized factors affecting VMA in the mix as shown in Table 3.

Stakston and Bahia (2003) found that gradation have the least influence on the response variables considered in their study, with the exception of the Voids in the Mineral Aggregates (VMA) where the effect on VMA is logical and was expected due to the fact that gradation controls the voids directly. Kandhal and Chakraborty (1996) reviewed researches presented the relationship between voids, surface area, film thickness and stability for dense graded mixtures. The authors recognized that thicker asphalt binder films produced mixes which were flexible and durable, while thin films produced mixes which were brittle, tended to crack and ravel excessively, retarded pavement performance, and reduced its useful service life. On the basis of the data they analyzed, average film thicknesses ranging from 6 to 8 microns were found to have provided the most desirable pavement mixtures also they stated that the best procedure for predicting the resistance of hardening of asphalt binder in a single-sized HMA mix was to calculate the ratio of the film thickness factor to permeability. The film thickness factor was defined as the ratio of the percent asphalt content available for coating the aggregate to the surface area of the aggregate. They concluded that the relationship between the asphalt film thickness and the aged properties (both short term and long term) of the HMA mixtures, such as tensile strength and resilient modulus, was quantified. A fairly good correlation was obtained between the asphalt film thickness and the resilient 
modulus of the aged HMA mixtures. An optimum film thickness of 9-10 microns was indicated from the data, below which the HMA mix (compacted to $8 \%$ air void content) aged at an accelerated rate. This range appears to concur with the results obtained by Goode and Lufsey in terms of air voids bitumen index ratio. Relationships were also established between the asphalt film thickness and the aged asphalt binder properties (both short and long term) such as viscosity, penetration, and complex modulus. An optimum film thickness of 9-10 microns was generally indicated from the data, below which the asphalt binder aged at an accelerated rate. This film thickness corresponds to asphalt binder contained in an HMA mix compacted to $8 \%$ air void content. The minimum VMA for the HMA mix used in this study was calculated to be $15.6 \%$ to accommodate an optimum asphalt film thickness of 9 microns and $4 \%$ air voids. The corresponding Asphalt Institute or Superpave recommendation for minimum VMA is $14 \%$ for this mix (maximum nominal size of $12.5 \mathrm{~mm}$ ). However, it may not be possible to achieve the desired VMA $(15.6 \%)$ in some dense-graded HMA mixtures of similar gradation.

The current Iraqi Specifications (1983) did not include any limitations for VMA as shown in Table 4 and for aggregate gradation and Table 5 for Marshall mixture specifications.

\section{Analysis and Discussion}

Two HMA mixtures with nominal maximum aggregate sizes of $12.5 \mathrm{~mm}$ (surface course) and $19 \mathrm{~mm}$ (binder course) have been considered. The mixtures were prepared under the current specifications where the aggregate selected in the middle of the specifications and the Surface Area were calculated using surface area factors from Table 1 as shown in Table 6 for both, surface and binder courses. Calculations of VMA were collected in Table 7 for surface and binder courses using equation (2) with a given values for specific gravity of asphalt $\left(\mathrm{G}_{\mathrm{b}}=1.047\right)$ and specific gravity of aggregate $\left(\mathrm{G}_{\mathrm{sb}}=2.463\right)$. Fig. 3 shows the effect of asphalt content on VMA for surface and binder courses mix. It can be noted that at optimum asphalt content $(5.5 \%)$ the VMA percentage (10\%) is not satisfied with the criteria of VMA (14\%) for surface layer. The same can be noted for binder layer (19mm) mixes for the effect of asphalt cement content on VMA where at optimum asphalt content (5\%), VMA is slightly more than $(10 \%)$ which is not satisfied for binder layer $(13 \%)$ as shown in the same figure.

The calculations of average film thickness were collected in Table 8 for surface course depending on equation (4) and related equations for the needed parameters. The same calculations were collected in Table (9) for binder course.

Fig. 4 shows the effect of asphalt content on film thickness. It is obviously can be noted that the relation is linear where increasing asphalt cement content will increase film thickness, this effect is expected because increasing asphalt content will increase voids filled with asphalt which in turn increases VMA. At optimum asphalt content (5.5\%) the film thickness is slightly more than 9 micron which is higher than the desired film thickness $(8$ micron) to obtain durable mixture. The same can be noted for binder course where the relation is linear too. At optimum asphalt content (5\%) for binder layer, film thickness is 9.65 micron.

To calculate the desired VMA assuming that film thickness is 8 microns and $4 \%$ air voids under the current aggregate gradation then, it can be found for surface layer by making use of Excel spread sheet facilities as follows:

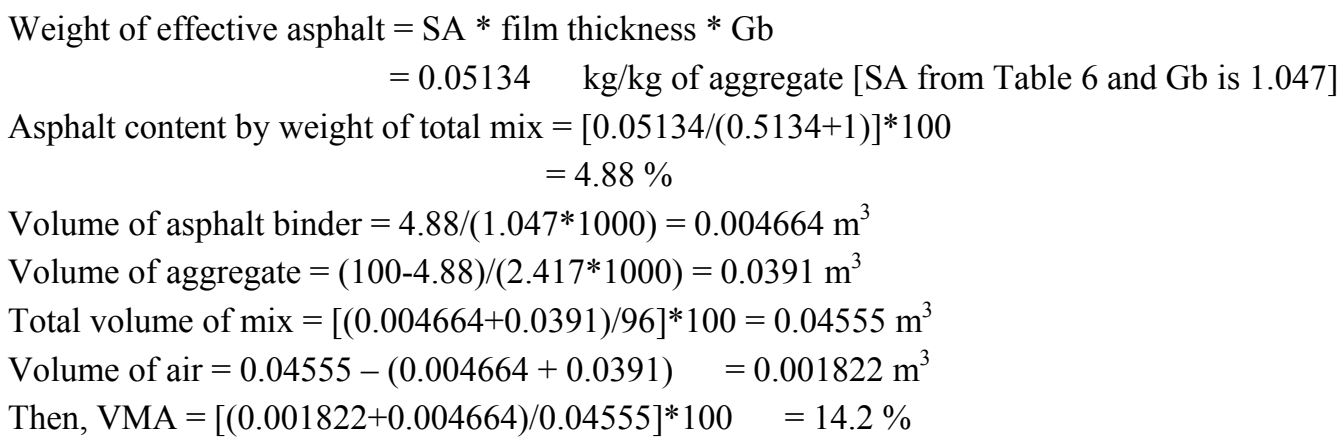

Although the mixtures were prepared under standard specifications, it can be noted that the asphalt content is under the optimum content. For binder course the calculated VMA is about $13 \%$ using $4.2 \%$ asphalt cement by weight of total mix. The increase in asphalt content is related to increase in surface area of aggregate where more binder is needed for coating all aggregate particles at same thickness of binder.

\section{Conclusions and Recommendations}

According to the studies being reviewed and work implemented in this study, the conclusions can be summarized as follows:

1) The volumetric parameters were derived for the first time by McLeod in 1956, and since that date the volumetric criteria for VMA was implemented in the Marshall and Superpave mix design methods while, in the current Iraqi standards, there is no limits for VMA for different layers of pavements. 
2) Mixture and aggregate specific gravity has significant influence in VMA calculations while, aggregate surface area has significant influence on optimum asphalt content.

3) The surface area factors used in the calculations of aggregate surface area were based on the percent passing of aggregate and this should be validated for the percent retained on each sieve.

4) There is an excess in asphalt cement content by $0.6 \%(5.5-4.9)$ for surface layer where comparing the asphalt content for mixes prepared by current standards with the asphalt content calculated by using VMA as criteria in the design of asphaltic mixture. The excess in asphalt content for binder layer is $0.8 \%(5.0-4.2)$ as compared by using the same calculations for surface layer.

5) Mixtures prepared under the current standards showed low content of VMA at optimum asphalt content and this can be explained by the effect excessive asphalt content on bulk specific gravity of mixture.

6) Increasing asphalt content will increase thickness of binder coating particles of aggregate by liner rate of first degree and this result is expected by logic. Average film thickness of 8 microns was recommended for durable mixtures as shown by previous studies.

7) Obtaining adequate VMA is an important part of the mix design which must be met. The challenge is to select aggregates which will give the proper amount of VMA without weakening the skeleton. Many mixtures meet the requirements without difficulty, others require more design work.

\section{Recommendation}

It is recommended that a minimum VMA criterion is that implemented by Asphalt Institute (Table 2) to be included with the current Iraqi standards with a tolerance of $1 \%$, and the recommended thickness of binder is 8 microns.

\section{References}

Anthony D. Stakston and Hussain Bahia. (2003). The Effect of Fine Aggregate Angularity, Asphalt Content and Performance Graded Asphalts on Hot Mix Asphalt Performance. WisDOT Highway Research Study 0092-45-98, Submitted to Wisconsin Department of Transportation Division of Transportation Infrastructure Development Research Coordination Section.

Asphalt Institute, the asphalt handbook, MS-4 7th edition, 2007.

Boris Radovs Kiy. (2003). Analytical Formulas for Film Thickness in Compacted Asphalt Mixture. Transportation Research Board, 82nd Annual Meeting, Washington, D.C.

Brian J. Coree and Walter P. Hislop. (1998). The Difficult Nature of Minimum VMA: A Historical Perspective.

David Diazgranados Diaz. (2003). Evaluation Of $4.75 \mathrm{~mm}$ Superpave Mix Criteria For West Virginia", Thesis submitted to the College of Engineering and Mineral Resources at West Virginia University in partial fulfillment of the requirements for the degree of Master of Science In Civil Engineering.

Jason W. Nelson. (2005). Comparison of $9.5 \mathrm{~mm}$ Superpave And Marshall Wearing I Mixes In West Virginia. Thesis submitted to the College of Engineering and Mineral Resources at West Virginia University in partial fulfillment for the degree of Master of Science in Civil Engineering.

John P. Zaniewski, Carlos H. Reyes. (2003). Evaluation Of The Effect Of Fines On Asphalt Concrete. Asphalt Technology Program, Department of Civil and Environmental Engineering, Morgantown, West Virginia.

P. S. Kandhal And L. A. Cooley, JR. (2001). National Center for Asphalt Technology, Auburn University, "The Restricted Zone In The Superpave Aggregate Gradation Specification", National Cooperative Highway Research Program, NCHRP Report 464, research sponsored by the American association of state highway and transportation officials in cooperation with the federal highway administration, transportation research board -national research council, national academy press, washington.

Prithvi S. Kandhal and Sanjoy Chakraborty. (1996). Evaluation Of Voids In The Mineral Aggregate For Hma Paving Mixtures", National Center for Asphalt Technology Auburn University, NCAT Report No. 96-4.

Prithvi S. Kandhal, Kee Y Foo and Rajib B Mallick. (1998). A Critical Review Of Vma Requirements In Superpave. NCAT Report No. 98-1.

Standard specification for roads and bridges, Department of design and studies, 1983.

T. Paul Teng. (2001). Superpave Mixture Design Guide. WesTrack Forensic Team Consensus Report, Washington, DC.

Thomas W. Kennedy, Gerald A. Huber, Edward T. Harrigan, Ronald J. Cominsky, Charles S. Hughes, Harold Von Quintus and James S. Moulthrop. (1994). Superior Performing Asphalt Pavements (Superpave)", The Product of the SHRP Asphalt Research Program. Strategic Highway Research Program, SHRP-A-410, National Research Council Washington.

Walter P. Hislop And Brian J. Coree. (2000). VMA As A Design Parameter In Hot-Mix Asphalt. Proceedings Mid-continent transportation symposium. 
Zanariah Bt Abd Rahman. (2006). Evaluation On Properties Of Tender Mixes. A project report submitted in partial fulfillment of the requirements for the award of the degree of Master of Engineering (Civil Transportation and Highway), Faculty of Civil Engineering, University Teknology Malaysia.

Table 1. surface area factor for different sizes of sieves, after Kandhal et.al. (1998)

\begin{tabular}{|c|c|c|c|c|c|c|c|c|}
\hline Sieve size, $\mathrm{mm}$ & 25 & 4.75 & 2.36 & 1.18 & 0.6 & 0.3 & 0.15 & 0.075 \\
\hline $\begin{array}{c}\text { Surface area factor, } \\
\mathrm{m} 2 / \mathrm{kg}\end{array}$ & 0.41 & 0.41 & 0.82 & 1.64 & 2.87 & 6.14 & 12.29 & 32.77 \\
\hline
\end{tabular}

Table 2. VMA requirements for different nominal maximum aggregate sizes, after Asphalt Institute (Zanariah 2006)

\begin{tabular}{||c|c||c|c|c||}
\hline \hline \multicolumn{2}{||c||}{$\begin{array}{c}\text { Nominal Maximum } \\
\text { Particle Size }\end{array}$} & \multicolumn{3}{c||}{ Minimum VMA, percent } \\
\cline { 5 - 5 } mm & \multicolumn{3}{c||}{ Design Air Voids, percent ${ }^{3}$} \\
\hline \hline 1.18 & No. 16 & $\mathbf{3 . 0}$ & $\mathbf{4 . 0}$ & $\mathbf{5 . 0}$ \\
\hline 2.36 & No. 8 & 21.5 & 22.5 & 23.5 \\
\hline 4.75 & No. 4 & 19.0 & 20.0 & 21.0 \\
\hline 9.5 & $3 / 8$ & 16.0 & 17.0 & 18.0 \\
\hline 12.5 & $1 / 2$ & 13.0 & 15.0 & 16.0 \\
\hline 19.0 & $3 / 4$ & 12.0 & 14.0 & 15.0 \\
\hline 25.0 & 1.0 & 11.0 & 13.0 & 14.0 \\
\hline 37.5 & 1.5 & 10.0 & 12.0 & 13.0 \\
\hline 50 & 2.0 & 9.5 & 11.0 & 12.0 \\
\hline 63 & 2.5 & 9.0 & 10.5 & 11.5 \\
\hline \hline
\end{tabular}

1 - Standard Specification for Wire Cloth Sieves for Testing Purposes, ASTM E11 (A.ASHTO M92)

2 - The nominal maximum particle size is one size larger than the firs sieve to retain more than 10 percent.

3 - Interpolate minimum voids in the mineral aggregate (VMA) for design air void values between those listed.

Table 3. Factors affecting VMA after Zanariah (2006)

\begin{tabular}{||l|l||}
\hline Factor & Effect on VMA \\
\hline \hline Aggregate Gradation & Dense gradations decrease VMA \\
\hline Aggregate Shape & More rounded aggregates decrease VMA \\
\hline Aggregate Texture & Smooth or polished aggregates decrease VMA \\
\hline Asphalt Absorption & $\begin{array}{l}\text { Increased asphalt absorption results in lower effective asphalt } \\
\text { content and lower VMA (for the same level of compaction) }\end{array}$ \\
\hline Dust Content & $\begin{array}{l}\text { Higher dust contents increase surface area, decrease film } \\
\text { thickness, and tend to lower VMA }\end{array}$ \\
\hline $\begin{array}{l}\text { Baghouse } \\
\text { Fines/Generation of Dust }\end{array}$ & $\begin{array}{l}\text { Increased fines and dust increase surface area, decrease film } \\
\text { thickness, and tend to lower VMA }\end{array}$ \\
\hline $\begin{array}{l}\text { Plant Production } \\
\text { Temperature }\end{array}$ & $\begin{array}{l}\text { Higher plant production temperatures decrease asphalt binder } \\
\text { viscosity, which results in more asphalt absorption, lower } \\
\text { effective asphalt binder and lower VMA }\end{array}$ \\
\hline $\begin{array}{l}\text { Temperature of HMA } \\
\text { during Paving }\end{array}$ & $\begin{array}{l}\text { Higher temperatures during paving create soft mixtures, lower } \\
\text { air voids, and lower VMA }\end{array}$ \\
\hline Hauling Time & $\begin{array}{l}\text { Longer hauling times allow for increased asphalt absorption, } \\
\text { lower effective asphalt content and lower VMA }\end{array}$ \\
\hline Aggregate Handling & $\begin{array}{l}\text { More steps in aggregate handling increases potential for } \\
\text { aggregate degradation, resulting in an increase in fines, and } \\
\text { lower VMA }\end{array}$ \\
\hline \hline
\end{tabular}


Table 4. Aggregate gradation for surface and binder courses after Iraqi Standards (1983)

\begin{tabular}{|c|c|c|c|}
\hline \multicolumn{2}{|c|}{} & \multicolumn{2}{c|}{ Percentage Passing by Weight of total Aggregate } \\
\hline $\mathrm{mm}$ & Imperial & Binder Course & Surface Course \\
\hline 25.0 & 1in & 100 & - \\
\hline 19.0 & $3 / 4$ in & $90-100$ & 100 \\
\hline 12.5 & $1 / 2$ in & $70-90$ & $80-100$ \\
\hline 9.5 & $3 / 8$ in & $60-80$ & $70-85$ \\
\hline 4.75 & N0.4 & $42-60$ & $60-80$ \\
\hline 2.0 & No.10 & $27-47$ & $40-60$ \\
\hline 1.0 & No.18 & $20-37$ & $28-48$ \\
\hline 0.60 & No.30 & $15-30$ & $22-40$ \\
\hline 0.25 & No.60 & $8-20$ & $10-30$ \\
\hline 0.125 & No.120 & $6-15$ & $8-20$ \\
\hline 0.075 & No.200 & $5-10$ & $6-12$ \\
\hline \multicolumn{2}{|c|}{ Asphaltic Cement } & $4-6$ & $4.5-6.5$ \\
\hline
\end{tabular}

Table 5. Specifications of asphalt mixes after Iraqi Standards (1983)

\begin{tabular}{|l|l|l|}
\hline \multirow{2}{*}{} & \multicolumn{2}{|c|}{ Binder Course } \\
\cline { 2 - 3 } & Min. 7KN & \multicolumn{1}{c|}{ Surface Course } \\
\hline Stability Marshall & $2-4 \mathrm{~mm}$ & $2-4 \mathrm{~mm}$ \\
\hline Flow Marshall & $3-7 \%$ & $3-5 \%$ \\
\hline Percentage voids in mix & Max. 1.0\% & Max. $1.0 \%$ \\
\hline $\begin{array}{l}\text { Swelling after 28 days\% } \\
\text { volume }\end{array}$ & Min.60-max.80 & Min.60-max.85 \\
\hline Voids filled with Bitumen (\%) & Min.80\% & Min.80\% \\
\hline $\begin{array}{l}\text { Index of Retained Strength } \\
\text { AASHTO T165 }\end{array}$ & & \\
\hline
\end{tabular}

Table 6. Aggregate gradation for surface course and binder course and Surface Area

\begin{tabular}{|c||c||c|c||c|c|}
\hline $\begin{array}{c}\text { Sieve Size, } \\
\mathrm{mm}\end{array}$ & $\begin{array}{c}\text { Surface Area } \\
\text { Factor, } \mathrm{m}^{2} / \mathrm{kg}\end{array}$ & $\begin{array}{c}\text { Mid Passing, } \\
\text { Surface } \\
\text { Course }\end{array}$ & $\begin{array}{c}\text { Surface Area, } \\
\text { Surface Course } \\
\mathrm{m}^{2} / \mathrm{kg}\end{array}$ & $\begin{array}{c}\text { Mid Passing, } \\
\text { Binder } \\
\text { Course }\end{array}$ & $\begin{array}{c}\text { Surface } \\
\text { Area, } \\
\text { Binder } \\
\text { Course } \\
\mathrm{m}^{2} / \mathrm{kg}\end{array}$ \\
\hline 25 & 0.41 & 100 & & 100 & 0.41 \\
\hline 19 & 0.41 & 100 & 0.41 & 95 & \\
\hline 12.5 & & 95 & & 78 & \\
\hline 9.5 & & 82 & & 68 & \\
\hline 4.75 & 0.41 & 58 & 0.2378 & 50 & 0.205 \\
\hline 2.36 & 0.82 & 40 & 0.328 & 36 & 0.2952 \\
\hline 1.18 & 1.64 & 30 & 0.492 & 26 & 0.4264 \\
\hline 0.6 & 2.87 & 22 & 0.6314 & 18 & 0.5166 \\
\hline 0.3 & 6.14 & 13 & 0.7982 & 12 & 0.7368 \\
\hline 0.15 & 12.23 & 10 & 1.223 & 8 & 0.9784 \\
\hline 0.075 & 32.77 & 6 & 1.9662 & 5 & 1.6385 \\
\hline & & & $\Sigma=6.0866 \mathrm{~m}^{2} / \mathrm{kg}$ & & $\Sigma=5.2069$ \\
$\mathrm{~m}^{2} / \mathrm{kg}$ \\
\hline
\end{tabular}


Table 7. VMA results for surface and binder courses

\begin{tabular}{|c|c|c||c|c|c|}
\hline \multicolumn{3}{|c||}{ Surface Course } & \multicolumn{3}{c|}{ Binder Course } \\
\hline $\begin{array}{c}\text { Mix Specific } \\
\text { Gravity }\end{array}$ & $\begin{array}{c}\text { Asphalt content by } \\
\text { weight, \% }\end{array}$ & VMA, & $\begin{array}{c}\text { Mix } \\
\text { Specific } \\
\text { Gravity }\end{array}$ & $\begin{array}{c}\text { Asphalt } \\
\text { content by } \\
\text { weight, } \%\end{array}$ & VMA, \\
\hline 2.183 & 4 & 14.9 & 2.177 & 3.5 & 14.7 \\
\hline 2.264 & 4.5 & 12.2 & 2.226 & 4 & 13.2 \\
\hline 2.293 & 5 & 11.5 & 2.303 & 4.5 & 10.7 \\
\hline 2.345 & 5.5 Optimum & 10 & 2.325 & 5 & 10.3 \\
\hline 2.321 & 6 & 11.4 & 2.316 & 5.5 & 11.1 \\
\hline
\end{tabular}

Table 8. Average film thickness calculations for surface course

\begin{tabular}{|c|c|c|c|c|c|c|}
\hline Parameter & \multicolumn{5}{|c|}{ Surface Course } & Source \\
\hline $\mathrm{P}_{\mathrm{b}}, \%$ & 4 & 4.5 & 5 & 5.5 & 6 & Given \\
\hline $\mathrm{G}_{\mathrm{mb}}$ & 2.183 & 2.264 & 2.293 & 2.345 & 2.321 & ASTM D 1559 (1989) \\
\hline $\mathrm{G}_{\mathrm{mm}}$ & 2.348 & 2.393 & 2.422 & 2.424 & 2.399 & ASTM D 2041 (1989) \\
\hline VTM, \% & 7.027257 & 5.3907229 & 5.3261767 & 3.2590759 & 3.2513547 & Eq. 1 \\
\hline VMA, $\%$ & 14.91352 & 12.215996 & 11.557044 & 10.02740 & 11.419407 & Eq. 2 \\
\hline $\mathrm{G}_{\mathrm{se}}$ & 2.4762053 & 2.5473082 & 2.6018385 & 2.6249255 & 2.6144971 & Eq. 9 \\
\hline $\mathrm{P}_{\mathrm{ba}}, \%$ & 0.2266962 & 1.4069239 & 2.2683598 & 2.6222893 & 2.4631940 & Eq. 8 \\
\hline $\mathrm{V}_{\mathrm{b}}, \%$ & 7.6595666 & 5.4183499 & 3.9625076 & 4.1460403 & 5.7048584 & Eq. 7 \\
\hline $\mathrm{w}_{\mathrm{b}}, \mathrm{kg}$ & 80.195662 & 56.730123 & 41.487455 & 43.409042 & 59.729867 & Eq. 6 \\
\hline $\mathrm{W}_{\text {agg }}, \mathrm{kg}$ & 1924.6958 & 1203.9392 & 788.26165 & 745.84627 & 935.76792 & Eq. 10 \\
\hline $\mathrm{W}_{\mathrm{b}}$ & 0.0416666 & 0.0471204 & 0.0526315 & 0.058201 & 0.0638297 & Eq. 5 \\
\hline TF,micron & $6.538 \mathrm{E}-06$ & 7.394E-06 & $8.258 \mathrm{E}-06$ & $9.132 \mathrm{E}-06$ & $1.001 \mathrm{E}-05$ & Eq. 4 \\
\hline
\end{tabular}

Table 9. Average film thickness calculations for binder course

\begin{tabular}{|l|l|l|l|l|l|l|}
\hline Parameter & \multicolumn{5}{|c|}{ Binder Course } & Source \\
\hline $\mathrm{P}_{\mathrm{b}}, \%$ & 3.5 & 4 & 4.5 & 5 & 5.5 & Given \\
\hline $\mathrm{G}_{\mathrm{mb}}$ & 2.177 & 2.226 & 2.303 & 2.325 & 2.316 & ASTM D 1559 (1989) \\
\hline $\mathrm{G}_{\mathrm{mm}}$ & 2.314 & 2.345 & 2.402 & 2.414 & 2.398 & ASTM D 2041 (1989) \\
\hline $\mathrm{VTM}, \%$ & 5.920484 & 5.0746268 & 4.1215653 & 3.6868268 & 3.419516 & Eq. 1 \\
\hline $\mathrm{VMA}, \%$ & 14.705440 & 13.237515 & 10.703816 & 10.32277 & 11.14007 & Eq. 2 \\
\hline $\mathrm{G}_{\mathrm{se}}$ & 2.4202249 & 2.4727301 & 2.5579914 & 2.592124 & 2.592712 & Eq. 9 \\
\hline $\mathrm{P}_{\mathrm{ba}}, \%$ & 0.0215145 & 0.1672730 & 1.5785843 & 2.1175597 & 2.126717 & Eq. 8 \\
\hline $\mathrm{V}_{\mathrm{b}}, \%$ & 8.7634419 & 7.9956152 & 5.0036668 & 4.5183905 & 5.593839 & Eq. 7 \\
\hline $\mathrm{w}_{\mathrm{b}}, \mathrm{kg}$ & 91.753237 & 83.714091 & 52.388391 & 47.30754 & 58.5674 & Eq. 6 \\
\hline $\mathrm{W}_{\mathrm{agg}}, \mathrm{kg}$ & 2529.7678 & 2009.1382 & 1111.7980 & 898.84342 & 1006.296 & Eq. 10 \\
\hline $\mathrm{W}_{\mathrm{b}}$ & 0.036269 & 0.0416666 & 0.0471204 & 0.0526315 & 0.058201 & Eq. 5 \\
\hline $\mathrm{TF}_{\mathrm{m}, \mathrm{micron}}$ & $6.652 \mathrm{E}-06$ & $7.642 \mathrm{E}-06$ & $8.643 \mathrm{E}-06$ & $9.654 \mathrm{E}-06$ & $1.06 \mathrm{E}-05$ & Eq. 4 \\
\hline
\end{tabular}


MASS

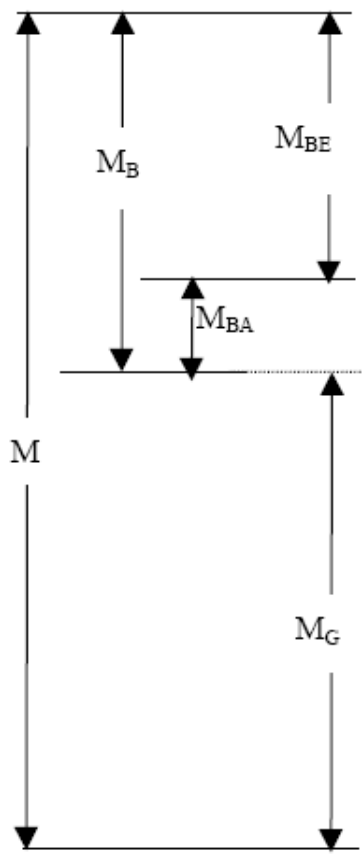

VOLUME
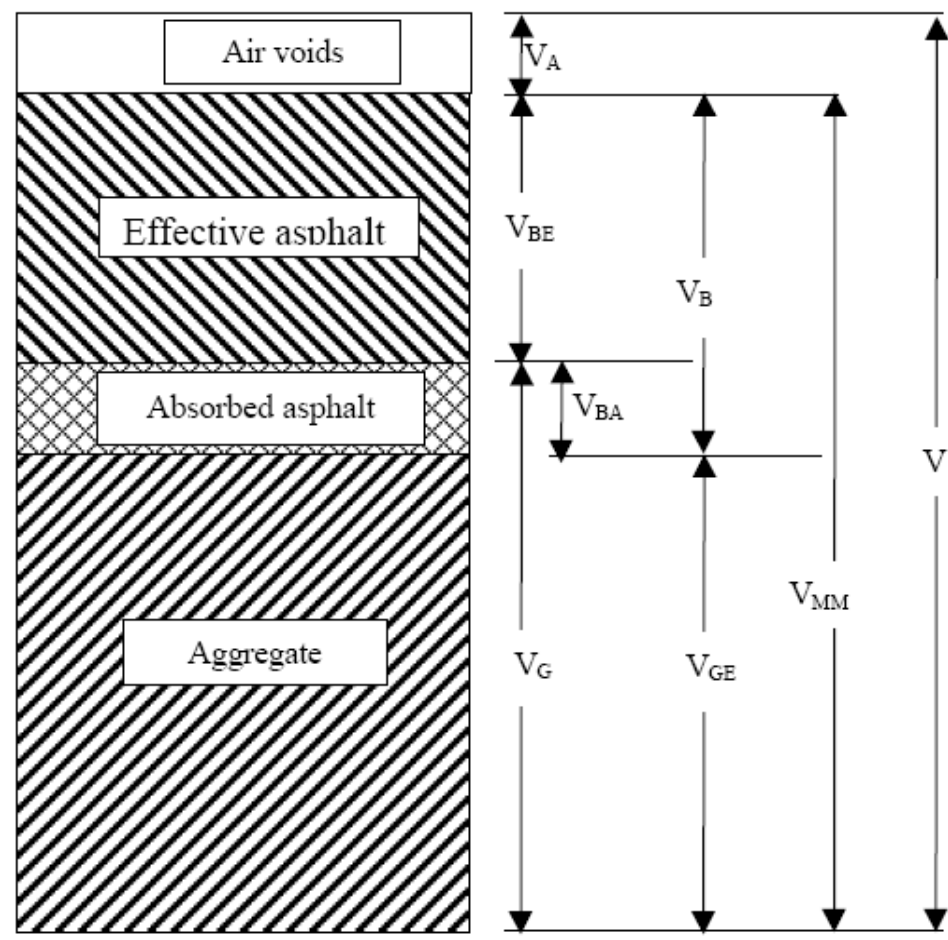

Figure 1. Component of hot mix asphalt

Where:

\section{Specimen}

$\mathrm{M}=$ Mass of specimen $(=\mathrm{MB}+\mathrm{MG})$

$\mathrm{V}=\mathrm{Bulk}$ volume of specimen

$\mathrm{VMM}=$ Volume of void-less mix

VA $=$ Volume of air between coated aggregate particles in the mix

\section{Binder}

MBA, VBA Mass \& volume of absorbed binder (within surface pores of aggregate particles)

MBE, VBE Mass \& volume of effective binder

MB Mass of constituent binder (= MBE+MBA)

VB Volume of constituent binder (= VBE+VBA)

Aggregate

$\mathrm{MG}=$ Mass of aggregate

$\mathrm{VG}=$ Bulk volume of aggregate (inclusive of all surface pores)

$\mathrm{VGE}=$ Effective volume of aggregate $(=\mathrm{VG}-\mathrm{VBA})$ 


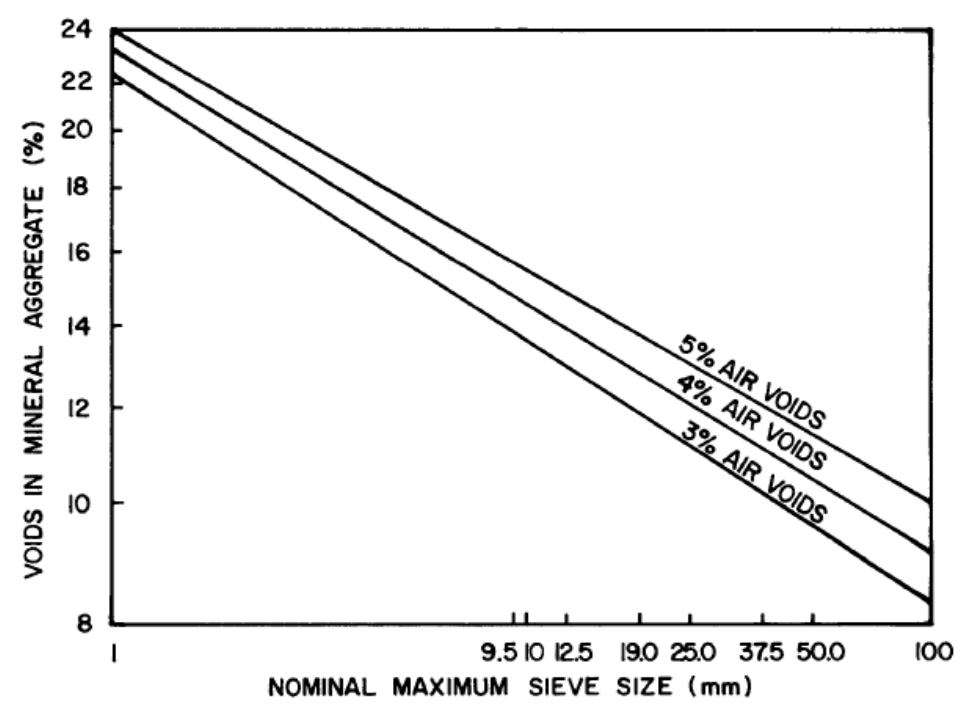

Figure 2. Recommended VMA for different aggregate sizes and air voids

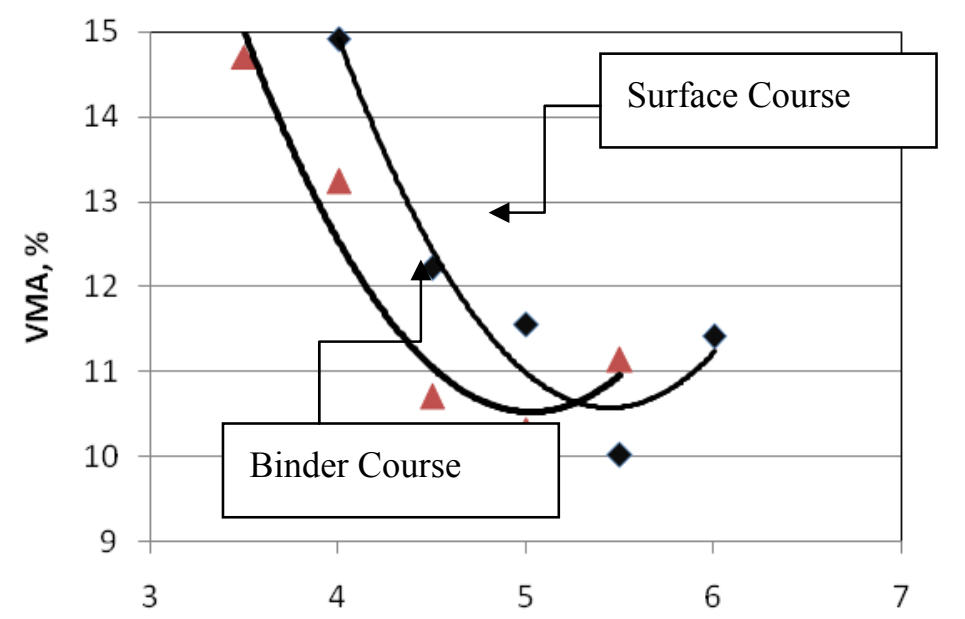

Asphalt content, by weight of total mix, \%

Figure 3. Effect of asphalt content on VMA for surface and binder courses

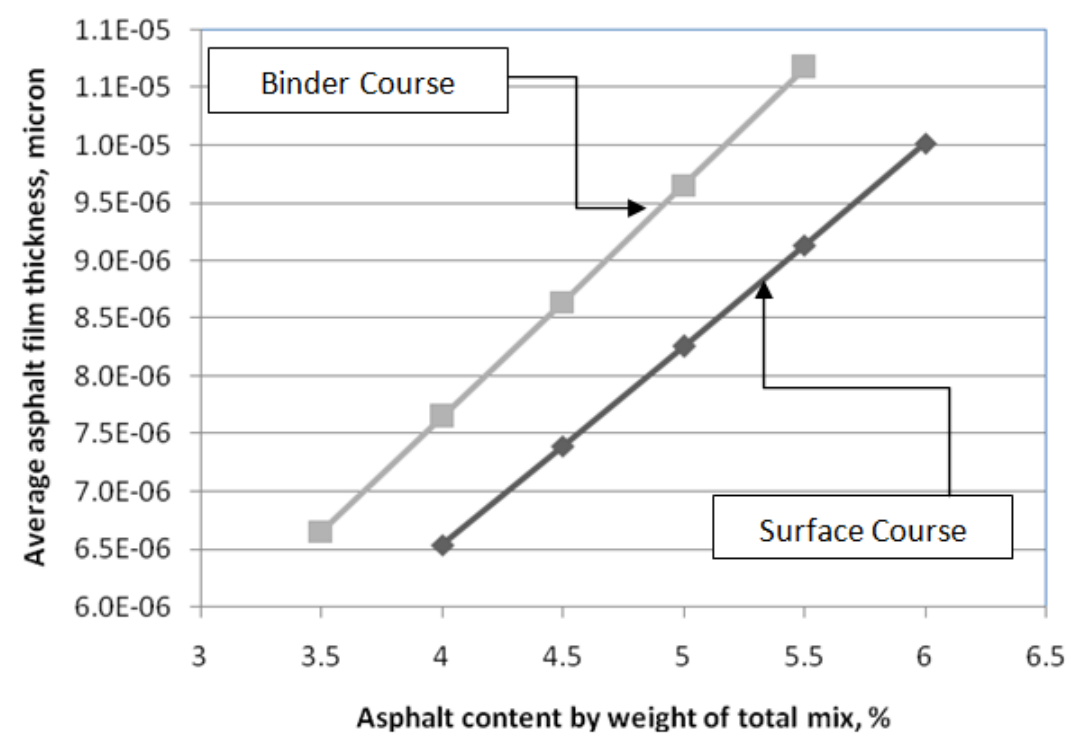

Figure 4. Effect of asphalt content on film thickness for surface and binder courses 